Hareketli protez

kullanan hastaların

oral hijyen

alışkanlıkları ve oral

mukozal lezyonlarla

ilişkisi

\section{Oral hygiene habits and relation with oral mucosal lesions of patients using removable dentures}

\author{
Araş. Gör. Fatma YÜCE \\ Necmettin Erbakan Üniversitesi, \\ Diş Hekimliği Fakültesi, Ağız, \\ Diş ve Çene Radyolojisi AD, Konya \\ Orcid ID: 0000-0002-9328-4895
}

\section{Doç. Dr. Melek TAŞSÖKER \\ Necmettin Erbakan Üniversitesi, Diş Hekimliği Fakültesi, Ağız, Diş ve Çene Radyolojisi AD, Konya Orcid ID: 0000-0003-2062-5713}

\section{Prof. Dr. Sevgi ÖZCAN}

Necmettin Erbakan Üniversitesi, Diş Hekimliği Fakültesi, Ağız, Diş ve Çene Radyolojisi AD, Konya Orcid ID: 0000-0002-2349-9292

\section{Geliş tarihi: 13 Aralık 2019}

Kabul tarihi: 20 Ağustos 2020

doi: 10.5505/yeditepe.2021.24855

\section{Yazışma adresi:}

Doç. Dr. Melek TAŞSÖKER

Necmettin Erbakan Üniversitesi, Diş Hekimliği

Fakültesi, Ağız, Diş ve Çene Radyolojisi AD

Karaciğan mh Ankara cd 74-A Karatay, 42050, KONYA Tel: 0-332-2200025-1236

E-posta: dishekmelek@gmail.com

\section{ÖZET}

Amaç: Bu çalışmanın amacı hareketli protez kullanan hastalarda görülen protezle ilişkili oral mukozal lezyonların (POML) sıklığı ve tiplerini belirlemek; yaş, cinsiyet, eğitim durumu, sistemik hastalık varlığı, sigara kullanımı, protez tipi, gece protez kullanımı ve oral hijyen durumu ile POML arasındaki ilişkiyi saptamaktır.

Gereç ve Yöntemler: Araştırmamız anket ve klinik muayene olmak üzere iki aşamadan oluşmaktadır. Anket formunda hastanın yaş, cinsiyet, sistemik hastalık varlığı, eğitim düzeyi, sigara kullanımı, diş hekimi ziyaret sıkığı, gece protez kullanım alışkanlığı, protez günlük bakım alışkanlığı ve protez kullanım süresi kayıt altına alınmıştır. Klinik muayenede POML varlığı (epulis fissuratum, protez stomatiti, mesnetsiz kret, travmatik fibrom, psödomembranöz kandidiyazis, angular şelitis, friksiyon keratozu, travmatik ülser) ve lokalizasyonu kaydedilmiştir. Çalışmadaki tüm parametreler için tanımlayıcı istatistikler hesaplanmıştır. Kategorik değişkenler arası ilişkilerin saptanmasında ki-kare testi kullanılmış olup, $\mathrm{p}<0,05$ seviyesinde anlamlı kabul edilmiştir.

Bulgular: Çalışmaya dahil edilen 133 bireyin yaş ortalaması 62,41 (41-88) yıldır. Değerlendirilen 227 parça protez bölgesinden 95 'inde POML saptanmıştır $(\% 41,8)$. Hastalarda en sık gözlenen POML protez stomatitidir $(\% 50,5)$. Protez kullanım süresi, protez temizleme sıklığı, gece protez kullanımı ve sigara alışkanlığı ile POML arasında istatistiksel olarak anlamlı ilişki saptanmıştır $(p<0,05)$. Eğitim seviyesi, sistemik hastalık varlığı, protezin tipi ve lokalizasyonu, protez temizleme ajanı ile POML arasında ilişki bulunmamıştır $(p>0,05)$.

Sonuç: Protezlerin günlük kullanım süresinin düzenlenmesi ve rutin oral hijyen alışkanlıklarıyla protezle ilişkili gelişen oral lezyonların azaltılması sağlanabilir.

Anahtar kelimeler: Hareketli protez, protez stomatiti, epulis fissüratum.

\section{SUMMARY}

Aim: The aim of this study was to determine the frequency and types of prosthetic associated oral mucosal lesions (POML) in patients using removable prostheses; and to establish the relationship between POML and age, sex, educational status, systemic disease, smoking, prosthesis type, usage of prosthesis at night and oral hygiene status.

Materials and Method: This study consists of two stages: questionnaire and clinical examination. Age, gender, systemic disease, education level, smoking, frequency of dental visit, the habit of using prosthesis at night, daily prosthesis care habits, and duration of prosthesis use were asked in the questionnaire form. The presence of POML (epulis fissuratum, prosthetic stomatitis, unrestrained crest, angular chelitis, traumatic fibroma, pseudomembranous candidiasis, frictional keratosis, traumatic ulcer) and localization were recorded at the time of clinical examination. Descriptive statistics were calculated for all parameters in the study. Chi-square test was used to determine the relationships between categorical variables 
and significance was considered at $\mathrm{p}<0.05$.

Results: The mean age of 133 individuals was 62.41 (4188) years. POML was detected in 95 of 227 prosthetic areas evaluated (41.8\%). Among all patients, denture stomatitis was the most common form of POML type (\%50.5). The frequency of POML increased significantly with denture age, frequency of prosthesis cleaning, usage of dentures at night, and smoking habit $(p<0.05)$. Educational status, systemic disease, dentures type and localization, prosthesis hygiene regimen and POML were not found to be related $(p>0.05)$.

Conclusion: Prosthesis-related oral lesions can be decreased by routine prosthesis hygiene regimen and regulate the duration of prosthesis usage.

Keywords: Removable denture, denture stomatitis, epulis fissuratum.

\section{GíRiş}

Dünya Sağlık Örgütü'nün (WHO) verilerine göre, son on yılda uygulanan birçok önleyici faaliyete rağmen, dünya çapında parsiyel veya tam diş kaybı olan çok sayıda insan mevcuttur. Özellikle gelişmekte olan ülkelerde bu oran 65 yaş üstünde çok yüksektir.' Ülkemizde 65-74 yaş grubunda görülen dişsizlik oranı ise \%48 olarak bildirilmiştir. ${ }^{2}$ Tam dişsizliğin görülme sıklığı geçmişteki kadar olmasa da diş hekimine hareketli protez intiyacı nedeniyle başvuran hasta sayısında azalma olmadığı belirtilmektedir. ${ }^{3}$ Bu durumun açıklaması modern toplumlarda yaşam süresinin uzamasına bağlı olarak yaşıı popülasyonun artması olabilir. ${ }^{4}$

Hareketli protezler (HP), parsiyel ya da tam diş eksikliği durumlarında sıklıkla tercih edilen bir tedavi seçeneğidir. Fonksiyonel ve estetik rehabilitasyonu sağlar. ${ }^{5}$ Hareketli protez kullanımı, yaşam kalitesini arttıran bir unsurdur; fakat protez bireye uygun olarak yapılmadıysa, kullanıcı protezine uygun şekilde bakımını yapamıyorsa ve belirli aralıklarla kontrol yapılmıyorsa proteze bağı olarak çeşitli lezyonlar oluşabilmektedir. ${ }^{6}$ Literatürde hareketli protez kullanan hastaların \%40-50'sinde protezle ilişkili oral mukozal lezyon (POML) görüldüğü bildirilmiştir.?

Protez materyalinin yüzeyinde oluşan biyofilm veya protezin yapıldığı materyale reaksiyon olarak ya da hatalı/ uyumsuz protezlerin dokuda oluşturduğu travma POML oluşmasına sebep olur. Protezlerin oral mukozayı örtmesi, protezlerin uyumsuzluğu, travma, yetersiz oral hijyen, yıpranmış-eski protezler, protezlerin sürekli kullanılması, protezlerin kullanım süresi de POML için risk faktörlerini oluşturmaktadır. ${ }^{8}$ Hastaların sistemik durumlarının ve yaşlarının da POML gelişimine katkıda bulunabileceği öne sürülmektedir. İlerleyen yaşla birlikte ağız mukozası mekanik yaralanmalara karşı savunmasız duruma gelmekte ve zararlı ajanlara karşı geçirgenliği artmaktadır. ${ }^{9}$ Ayrıca yaşlılarda tüm bu faktörlere ek olarak, ilaç kullanımı, tü- kürük miktarı ve kalitesindeki değişikliklerin de kandida enfeksiyonlarını ve travmatik ülserleri artırabileceği öne sürülmüştür. ${ }^{8}$

Hareketli protez kullanan hastalarda en sık görülen POML tipi protez stomatitidir. Protez stomatiti, hareketli protezler tarafından örtülen mukozanın inflamatuvar bir reaksiyonudur. Etiyolojisi multifaktöriyeldir ve epidemiyolojik çaıışmalarda görülme sıklığı \%15-70 arasında olduğu ortaya konulmuştur. Oral kandida enfek`siyonu, oral mukozada travma ve protez hijyeninin sağlanamaması protez stomatiti ile ilişkili bulunmuştur. ${ }^{10-12}$ Protezlerin gece takılmasının protez stomatiti gelişiminde en önemli risk faktörü olduğu kabul edilmektedir. ${ }^{13}$

Epulis fissuratum, uyumu bozuk parsiyel ya da total protezlerin kenarları boyunca gelişmektedir. Fibröz inflamatuvar hiperplazi olarak da isimlendirilir. Geniş protez sınırlarının neden olduğu aşııı basınç ve oklüzyon bozukluğuna bağlı devirici kuvvetlerle oluşan travma ve inflamasyondan kaynaklanır. Genellikle 5-7. dekatlarda, görülmektedir. Genellikle koyu kırmııı renkte ve sert kıvamlıdır; epulisin büyüklüğü, gelişim süresine ve travmanın derecesine bağlıdır. ${ }^{6,14-16}$ Tipik olarak asemptomatiktir. ${ }^{17}$

Uzun süreli hareketli protez kullanan hastalarda protezin kapladığı alveolar kemiğin fibröz, hiperplastik dokuyla yer değiştirmesine mesnetsiz kret denilmektedir. ${ }^{8,18}$ Protez kullanım süresinin ve kalitesinin mesnetsiz kret görülmesiyle ilişkili olduğu belirtilmiştir. Özellikle maksillanın tam dişsiz mandibulada dişlerin mevcut olduğu durumlarda maksilla anteriorda, nadiren de olsa mandibula posteriorda görülmektedir. ${ }^{19}$

Angular şelitis, sıklıkla bilateral, parlak kırmızı, eritemli fissürler şeklinde komissura alanlarında görülen inflamasyondur. ${ }^{8,18}$ Oluşmasında hem lokal hem sistemik faktörler etkilidir. ${ }^{20}$ Uyumsuz protezler, tam dişsizlik hali, düşük okluzal dikey boyut ve yaş angular şelitisle ilişkili bulunmuştur. 8,18

Çalışmamızda yaş sınırlaması yapılmaksızın, hareketli protez kullanan hastalarda görülen POML sıklığı ve tipleri lokalizasyonları ile birlikte tespit edilmeye çalışılmıştır. Hastaların yaşı, cinsiyeti, eğitim durumu, sistemik hastalık varlığı, sigara kullanımı, protez tipi, gece protez kullanımı ve oral hijyen seviyesi ile POML arasındaki ilişki araştırımıştır.

\section{GEREÇ VE YÖNTEM}

Çalışma, 2019 yılında Necmettin Erbakan Üniversitesi Diş Hekimliği Fakültesi Ağız, Diş ve Çene Radyolojisi kliniğine çeşitli şikayetlerle ilk muayene amacıyla başvuran hareketli protez kullanan hastalarla yürütülmüştür. Araştırma için gerekli etik onay Necmettin Erbakan Üniversitesi Diş Hekimliği Fakültesi illaç ve Tıbbi Cihaz Dışı Araştırmalar Etik Kurulu'ndan (\#2019/09) alınmıştır. Araştırmamız çaışmaya katılmaya gönüllü olan bireylerin yazılı onamları 
alındıktan sonra Helsinki Deklerasyonu Prensipleri'ne uygun şekilde yürütülmüştür.

Çalışmada 40 yaş üstü,53'ü erkek, 80'i kadın olmak üzere toplam 133 hasta muayene edilmiştir. Protez tipi olarak bir kısıtlama yapılmayıp tam, parsiyel veya implantüstü protez kullanan tüm hastalar çalışmaya dahil edilmiştir. Protezini herhangi bir nedenle 2 hafta boyunca düzenli takmayan hastalar çalışma dışında tutulmuştur.

Araştırmamız anket ve klinik muayene olmak üzere iki aşamadan oluşmaktadır. Hastaların klinik muayeneleri ve anket bilgilerinin kaydı tek bir klinisyen tarafından gerçekleştirilmiştir. Anket formunda hastanın şikayeti, yaşı, cinsiyeti, sistemik hastalık varlığı, eğitim düzeyi, diş hekimi ziyaret sıklığı, protez günlük bakım alışkanlığı (protez temizleme ajanı ve sıklığı), gece protez kullanım alışkanlığı, sigara kullanımı, ve protez kullanım süresi kayıt altına alınmıştır. Klinik muayenede POML varlığı (epulis fissuratum, protez stomatiti, mesnetsiz kret, travmatik fibrom, psödomembranöz kandidiyazis, angular şelitis, friksiyon keratozu, travmatik ülser) ve lokalizasyonu kaydedilmiştir. POML tanısı sadece klinik muayene ile konularak histopatolojik doğrulama yapılmamıştır. Hastalara mevcut oral lezyonları hakkında bilgi verilmiş ve hastalar tedavileri için ilgili kliniklere yönlendirilmiştir.

istatistiksel analiz

Verilerin analizi için SPSS V.21 yazılımı (IBM Corp.,Armonk, NY, USA) kullanılmıştır. Çalışmadaki tüm parametreler için tanımlayıcı istatistikler hesaplanmıştır. Kategorik değişkenler arası ilişkilerin saptanmasında ki-kare testi kullanılmış olup, $\mathrm{p}<0,05$ seviyesinde anlamlı kabul edilmiştir.

\section{BULGULAR}

Çalışmaya dahil edilen 133 bireyin yaş ortalaması 62,41 (41-88) yıldır. 53 erkek hasta için yaş ortalaması 63,94 yıl iken (48-87), 80 kadın hasta için yaş ortalaması 61,40 yıldır (41-88). POML saptanan bireylerin yaş ortalaması 62,94 yıldır (47-79). Yaş ile POML arasında istatistiksel anlamlı ilişki görülmemiştir ( $p>0,05)$.

133 hastanın 58'inde $(\% 43,6)$ farklı tiplerde POML saptanmıştır. Hastalar arasında en sık gözlenen POML tipi, protez stomatiti olmuştur $(\% 50,5)$. Çalışmamızda en sık karşılaşılan diğer POML tipleri sırasıyla \%18,9 ile epulis fissuratum, $\% 9,5$ ile travmatik ülser olmuştur. En az rastlanan POML tipi ise \%2,1 ile friksiyon keratozudur (Tablo 1).

Tablo 1. Hastalarda gözlenen POML tipleri.

\begin{tabular}{|c|c|c|c|c|c|c|c|c|c|}
\hline POMl. tipi & $\begin{array}{c}\text { Protez böletsis, } \\
\text { N }\end{array}$ & $\begin{array}{c}\text { Maksilla } \\
\text { n }\end{array}$ & Manabuth & $\begin{array}{c}\text { Mukaca } \\
\text { n }\end{array}$ & Kadin & $\begin{array}{c}\text { Erkek } \\
\mathrm{n}\end{array}$ & $\begin{array}{c}\text { Total prouta } \\
\text { n }\end{array}$ & $\begin{array}{c}\text { Parsiyt protez } \\
\text { n }\end{array}$ & $\%$ \\
\hline Equlis fisturtant & 18 & 10 & 8 & - & 9 & 9 & 10 & 8 & 189 \\
\hline Procez stomaxil & 48 & 41) & 8 & - & 20 & 19 & 2) & 28 & 505 \\
\hline Nesestiz kret & 5 & 5 & & . & 1 & 4 & 2 & 3 & 53 \\
\hline Trasnatik fibren & 4 & 2 & . & 2 & 4 & 0 & 1 & 3 & 4,2 \\
\hline 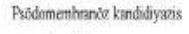 & 6 & 6 & - & - & 2 & 4 & 4 & 2 & 6.3 \\
\hline Angular seltos & 3 & - & . & 3 & 2 & 1 & 2 & 1 & 3,2 \\
\hline Friksygon keratcecu & 2 & 1 & . & 1 & 1 & 1 & 0 & 2 & 2,1 \\
\hline Trambatik oler & 9 & 5 & 4 & & 4 & 5 & 5 & 4 & 95 \\
\hline Tise] & $5(\mathrm{~S})(0)$ & $89(2,6)$ & 300211 & 69664 & 520654.72 & $43(945,3)$ & $4(3463)$ & $51(0,537)$ & 1000 \\
\hline
\end{tabular}

133 hastadan 19 adet tek parça üst, 20 adet tek parça alt ve 94 adet alt-üst hareketli olmak üzere toplam 227 parça protez bölgesi incelenmiştir. 227 bölgenin değerlendirilmesi sonucunda 58 hastada (30 erkek, 28 kadın) toplam 95 protez yerleşim alanında POML saptanmıştır (\%41,8). POML görülen bölgelerin 44'ünde $(\% 46,3)$ total protez, 51 'inde $(\% 53,7)$ parsiyel protez varlığı saptanmıştır. Protez tipi ile POML arasında anlamlı bir ilişki saptanmamıştır ( $p>0.05)$. POML görülme oranı, birey bazında incelendiğinde erkeklerde \%56,6; kadınlarda \%35,0 olarak bulunmuştur. Erkek cinsiyet, POML görülme sıklığını anlamlı derecede arttırmıştır $(p<0,05)$.

Çalışmaya dahil edilen hastaların tamamı 'şikayetim olduğunda diş hekimine giderim' yanıtını vermiş olup, başvuru şikayetlerine göre dağılımları Tablo 2'de verilmiştir.

Tablo 2. Çalışmaya dahil edilen hastaların kliniğimize başvuru sebepleri ve da ğılımları.

\begin{tabular}{lrr}
\hline Hasta Şikayeti & Kişi Sayısı(n) & Yüzde (\%) \\
\hline Diş ağrısı & 30 & 22,6 \\
Diş çektirmek & 8 & 6 \\
Diş hassasiyeti & 2 & 1,5 \\
Diş tedavisi & 10 & 7,5 \\
Halitozis & 1 & 0,8 \\
İmplant isteği & 2 & 1,5 \\
Oral lezyon & 1 &, 8 \\
Periodontal problem & 21 & 15,8 \\
Proteze bağlı șikayetler & 26 & 19,5 \\
Protez yenileme & 5 & 3,8 \\
Tme-Bruksizm & 27 & 20,3 \\
Total & 133 & 100,0 \\
\hline
\end{tabular}

Hastalar en çok diş ağrısı şikayetinden dolayı ( $n=30$, $\% 22,5)$ muayene olmak için başvurmuştur. Protez kaynakIı bir şikayetle başvuranların sayısı 31 (\%23,3) kişidir.

HP kullanan hastaların \%50,3'ünün sistemik hastalığının olduğu ve sistemik olarak en sık görülen durumun hipertansiyon ( $n=22, \% 32,8$ ) olduğu saptanmıştır. Diyabet $(\% 23,8)$ ve kardiyovasküler hastalıklar $(\% 11,9)$ sırayla en yüksek gözlenen diğer sistemik hastalıklardır. Ancak sistemik hastalık varlığı ile POML arasında anlamlı ilişki saptanmamıştır $(p>0,05)$.

Çalışmamıza katılan hastaların eğitim durumları; eğitim almamış (\%12), ilköğretim mezunu $(\% 77,4)$ ve lise/lise üzeri eğitim alanlar $(\% 10,6)$ olarak üçe ayrıımıştır. Çalışmadaki katıımcıların büyük çoğunluğunu ilköğretim mezunu olan grup oluşturmuştur. Eğitim durumu ile POML arasında istatistiksel olarak anlamlı ilişki görülmemiştir $(p>0,05)$. Protez kullanım süresi, <5 yıl, 6-10 yıl, >10 yıl olmak üzere 
üç gruba ayrılmıştır. Protezini <5 yıl kullanan 44 bireyde POML görülme sıklığı \%31,8; 5-10 yıl arasında kullanan 54 bireyde $\% 44,4 ;>10$ yıl kullanan 35 bireyde $\% 57,1$ olarak bulunmuştur. Protez kullanım süresi arttıkça POML artış göstermiştir $(p<0,05)$.

Protez temizleme sıklığının POML ile istatistiksel anlamlılık gösterdiği ve temizleme sıklığı arttıkça POML'un azaldığı tespit edilmiştir, her gün protezini temizleyen hastalarda POML sıklığı anlamlı olarak daha azdır. $(p<0,05)$. Katılımcıların \%83,4'ü ( $n=111)$ protezlerini her gün temizlediğini, $\% 60,1^{\prime} i$ ( $n=80$ ) protezlerini gece çıkarmadığını belirtmişlerdir.

Protez temizlemek için bireyler en çok diş macunu-fırça kullanmıştır ( $n=70, \% 52,6)$. Diş macunu-fırça haricinde protez temizliğini sağlamak için sadece su, sabun, çamaşır suyu ve protez temizleme tabletleri de hastalar tarafından kullanılan yöntemlerdendir. POML varlığı ve protez temizleme ajanları arasında anlamlı bir ilişki saptanmamıştır ( $p>0,05)$. POML varlığı ile araştırılan parametrelerin ilişkisi Tablo 3'te gösterilmiştir.

Tablo 3. POML varlığının çalışma parametreleri ile ilişkisi ve hastaların bu parametrelere göre dağılımları.

\begin{tabular}{|c|c|c|c|}
\hline Kiṣi sayıs ( $\mathrm{n}=133$ hasta üzerinden) & P değeri & Kiṣi sayıs ( $\mathrm{n}=133$ hasta uีzerinden) & $\bar{P}$ değeri \\
\hline Yas & 0,787 & Protez temizleme shliğt & $0,003^{3}$ \\
\hline Cinsiyet & $0,020^{*}$ & Her gün $(111)(\% 83,4)$ & \\
\hline Sistemik hastalik & 0,296 & Haftada bir (22) $(\% 16.4)$ & \\
\hline $\operatorname{Var}(67)(\% 50,3)$ & & Protez temizleme ojam & 0,325 \\
\hline Yok $(60)(\% 49,7)$ & & Diş macunu-firça $(70)(\% 52,0)$ & \\
\hline Hipertansiyon $(22)(\% 32,8)$ & & Sabun $(20)(\% 15,0)$ & \\
\hline Diabet $(10)(\% 23,8)$ & & $\mathrm{Su}(30)(\% 22,5)$ & \\
\hline Hipertansiyon+Diğer hastallklar $(15)(\% 22,3)$ & & Tablet (7) (\%0.52) & \\
\hline Kalp hastaliklan $(8)(\% 11,9)$ & & Çamaşır suyu (4) $(\% 0,3)$ & \\
\hline Tiroit hastallklan (2) (\%0.29) & & Dig̉er (2) (\%0.15) & \\
\hline Diğer durumlar (4) (\%0.59) & & Sigara kullamm yok (114) $(9685,7)$ & $0,016^{*}$ \\
\hline Eğitim Dưrumu & 0,450 & Sigara kullanmm var (19) (9614,3) & \\
\hline Eg̃itim almamıș $(16)(\% 12,0)$ & & Günde 10 'dan az (4) $(\% 21,1)$ & \\
\hline Illküretim $(103)(\% 77,4)$ & & Günde 10 adet $(3)(\% 15,7)$ & \\
\hline Lise ve izzeri $(14)(\% 10.6)$ & & Gunde $10-20$ aras $(8)(\% 42,1)$ & \\
\hline Protesin killanmm süresi & $0,024^{*}$ & Gonde 20 den fazla $(4)(\% 21,1)$ & \\
\hline$\leq 5$ yl $(44)(\% 33,0)$ & & Gece protez kullanims & $0,000^{*}$ \\
\hline $6-10 \mathrm{Yul}(54)(\% 40,6)$ & & $\operatorname{Var}(80)(\% 60.1)$ & \\
\hline$>10$ yil $(35)(\% 26,4)$ & & Yok $(53)(\% 39,9)$ & \\
\hline
\end{tabular}

Sigara kullanımının POML ile istatistiksel anlamlılık gösterdiği tespit edilmiştir $(p<0,05)$. Günlük sigara kullanım adedi arttıkça hastalarda POML görülme sıklığı artmış; 20+ adet sigara kullanan hastaların hepsinde POML saptanmıştır. Katılımcıların \%85,7'si sigara içmekteydi ve sigara içen bireylerin $3 / 4$ 'ünü erkek katılımcılar oluşturmaktaydı. Sigara kullanan bireylerin \%36,8'i günde 0-10 adet, \%42,1'i 10-20 adet, \%21'i 20+ adet sigara içmekteydi.

Gece protezini çıkarmayan hastalarda POML görülme oranı \%60, gece protez takmayan hastalarda $\% 18,8$ olarak bulunmuştur. Gece protez kullanımı ile POML varlığı arasında $p=0.000$ derecesinde istatiksel olarak anlamlı ilişki saptanmıştır.

\section{TARTIŞMA}

Hareketli protez kullanımı gelişen alternatif yöntemlere rağmen hala yaşılar arasında çok yaygındır. HP çok iyi bir oral rehabilitasyon türüdür, ancak doğru kullanılmadığında çeşitli mukozal lezyonlara neden olmaktadır. ${ }^{21,22} \mathrm{Bu}$ çalışmanın amacı fakültemize başvuran hareketli protez kullanan hastalarda POML sıklığı ve tiplerini belirlemek; hastaların yaşı, cinsiyeti, eğitim durumu, sistemik hastalık varlığı, sigara kullanımı, protez tipi, gece protez kullanımı ve oral hijyen alışkanlıkları ile POML arasındaki ilişkiyi saptamaktır. Yaşlı hastaların diş hekimi kontrolüne gitme konusunda isteksiz oldukları, dolayısıyla protez kullanım süresinin arttığını ve bu nedenle POML geliştiği yapılan çalışmalarda ifade edilmiştir. ${ }^{18}$

Çalışmamızda yer alan hastaların yaş aralığı 41-88 arasında değişmektedir. POML görülme sıklığı genellikle yaşlılarda gençlerden daha yüksek bulunmakla birlikte, bu çalışmada yaşla POML varlığı arasında bir ilişki bulunmamıştır (Tablo 3).8,9 Bireylerin yaşı; oral hijyen durumu, protez kullanım alışkanlıkları gibi diğer faktörlerle birlikte POML gelişimine yol açabilir ancak tek başına önemli bir etkiye sahip olmadığı belirtilmiştir. ${ }^{8}$ Bunun yanı sıra bireylerin yaşının, bazı POML tipleri (protez stomatiti, travmatik ülser) için belirleyici olduğu öne sürülmüştür. ${ }^{23}$

133 birey ile yapılan bu çalışmada toplam 58 hastada (30 erkek, 28 kadın) POML varlığı tespit edilmiştir. Erkeklerin \%56,6'sında, kadınların \%35,0'ında POML görülmüştür. Birey bazında incelendiğinde erkeklerde POML görülme sıklığı anlamlı olarak daha yüksek bulunmuştur. Erkek cinsiyetin oral hijyen alışkanlıklarının kadınlara göre yetersiz olması bu sonuçta etkili olabilir. Yapılan önceki çalışmalarda ise cinsiyet ve POML arasında anlamlı ilişki olduğunu bildiren ve aksini gösteren bulgular elde edilmiştir.8,24,25 Çalışmalarda elde edilen farklı sonuçların da örneklem büyüklüklerinin farkııı̆ı, kadın-erkek cinsiyet dağılımında çeşitlilik olması, hastaların var olan protezi kullanma sürelerinin farklı olması ya da oral bakım alışkanlıklarının kadın-erkek arasında farklılık göstermesi ve bu parametrelerin de POML oluşumunda etkili olabileceği gerçeği de göz önünde bulundurulmalıdır.

Çalışmamız dahilinde 133 hastada toplam 227 bölge incelenmiş olup, 95 adet POML $(\% 41,8)$ saptanmıştır. Literatüre bakıldığında, POML görülme sıklığı \%40-50 arasında değişmektedir. ${ }^{7,8,26}$ Çalışmalarda elde edilen farklı sonuçlar, örneklemler arasındaki demografik farklılıklar, araştırmacıların kullandığı diagnostik kriterler ve metodolojik farklılıklardan kaynaklanabilir. ${ }^{27}$ Örneklem grubunun büyüklüğü, cinsiyet dağılımı ve yaş aralıklarındaki değişkenlikler de bir diğer etkili faktör olarak düşünülebilir. Çaışmada yer alan bireylerin kullandıkları HP tipi ile POML arasında ilişki bulunamamıştır. Kullanılan protez tipinin, POML görülme sıklığına etkisi olmadığı yapılan diğer çalışmalarda da belirtilmiştir., ${ }^{9,25}$ 
HP kullanan hastalarda genellikle en sık görülen POML tipi protez stomatitidir. ${ }^{8,21,27}$ Bu çalışmada da hastalarda en çok protez stomatiti görülmüştür (\%50.5). Kötü oral hijyen, gece protez kullanımı gibi durumlar protez stomatitinin altında yatan en büyük etiyolojik faktörlerdir. Uyumu bozulmuş, oral mukozayı irrite eden protezlerden kaynaklanan epulis fissuratum ise ikinci en sık görülen POML tipidir. ${ }^{6}$ Kadın hastaların estetik amaçlı olarak daha uzun süre ve daha sık protez takmalarının, POML görülme sıklığının artmasına sebep olduğu düşünülmektedir. ${ }^{29}$ Geçmişte sadece bir veya birkaç POML tipinin incelendiği daha spesifik çalışmalar bulunmaktadır. ${ }^{6,25}$ Bu çalışmalarda incelenen bazı POML tiplerinin cinsiyete bağlı olarak görülme sıklığının anlamlı olarak değiştiği belirtilmesine rağmen örneklem grubumuzun büyüklüğü bu tarz bir değerlendirmeyi yapmak için yeterli görünmemektedir.

Çalışmamızdaki katıımcıların 66'sı sistemik olarak sağlıklı, 67'si ise çeşitli sistemik hastalıkları bulunan bireylerdi ve POML ile sistemik hastalık varlığı arasında istatistiksel anlamlı bir ilişki saptanmadı. Erçalık ve ark.'ın ${ }^{24} 400$ bireyle, Akkaya ve ark.'ın ${ }^{8} 199$ bireyle yaptıkları çalışmalarında sistemik hastalık ve POML arasında pozitif yönde anlamlı ilişki bulunmuştur. Bu çalışmada anlamlı bir ilişkinin olmamasının nedeni örneklem büyüklüğü ile ilişkilendirilebilir. Katılımcı sayısı ( $n=133$ ) bu çalışmanın limitasyonu olarak görülebilir.

Katılımcıların çoğunlukla $(\% 77,4)$ ilköğretim mezunu olduğu görülen çalışmamızda eğitim seviyesi ile POML varlığı arasında herhangi bir ilişki bulunamamıştır. POML sıklığı ile eğitim durumu arasında negatif yönde ilişki bulunan çalışmalarda, çalışmanın yapıldığı yerdeki bölgesel farklılıklar ve bunun sonucu olarak demografik yapının değişmesi göz önünde bulundurulmalıdır. Eğitim seviyesi oral hijyeni sağlamada etkili bir unsurdur. ${ }^{8,30}$

Protez kullanım süresine göre 3 gruba ayrılan katıımcılardan, protezini > 10 yıldır kullananlarda ( 35 birey) POML görülme oranı \%57,1 olarak bulunmuştur. Benzer araştırmaların7,14,24,31 sonuçlarıyla uyumlu olarak çalışmamızdaki bireylerin protez kullanım süresi arttıkça POML görülme oranı artış göstermiştir. Moskona ve Kaplan ${ }^{32}$ yaşlı hastaların protezlerini çıkarma konusunda isteksiz olduklarını dolayısıyla protez kullanım süresinin ve buna bağlı olarak POML görülme olasılığının artıı̆ını belirtmişlerdir.

Hastaların protez temizleme sıklığı ile POML varlığı arasında anlamlı ilişki görülmüştür. Her gün protezini temizleyen hastalarda POML sıkığı anlamlı olarak daha azdır. Protez temizleme sıklığının artması ağız içinde ve protez yüzeyinde oluşan biyofilm tabakasının bozulmasını, mikrobiyal ekolojinin sağlıklı yönde değişmesini sağlamaktadır. ${ }^{21}$ Bulgularımızın aksine yapılan bazı çalışmalarda; oral hijyen ile POML arasında bir ilişki bulunmadığı ifade edilmiş, bu sonuç doku uyumu kötü olan protezlerin sebep olduğu travmatik etkiye bağlı olarak oral hijyen seviyesi yük- sek olan bireylerde bile POML gelişiminin pozitif olmasına bağlanmıştır. ${ }^{23}$

Bulgularımıza göre hastalar protezlerini temizlemek için en sık diş macunu ve fırçası tercih etmektedir. Diş macunu ve fırça kullanımının yaygın olması nispeten ucuz olmaları ve hastaların sıradan diş temizleme yöntemlerinin protez temizliği için de yeterli olduğunu düşünmelerinden kaynaklanmaktadır. ${ }^{33-35}$ Jagger ve Harison ${ }^{36}$ yaptıkları çalışmada hastaların protezlerini tam olarak nasıl temizlemeleri gerektiğini bilmediklerini belirtmişlerdir. Çalışmamızda aldığımız yanıtlar da göz önüne alınırsa hastaların protetik tedavi gerekliliklerinin yanı sıra oral hijyenin sürdürülmesine yönelik eğitime de intiyaçları olduğu düşünülmektedir ve diş hekimleri bu konunun daha fazla üzerinde durmalıdır.

Sigara içen kişilerin çoğunlukta olduğu çalışmamızda, sigara içenlerin \%75'i erkekti ve \%21'i günde $20+$ sigara kullanmaktaydı. Günlük sigara kullanım adedi arttıkça hastalarda POML görülme sıklığı artmış; 20+ adet sigara kullanan hastaların hepsinde POML saptanmıştır. Çalışma grubumuzun yer aldığı yaş aralığında oral mukozanın incelmesi ve direncinin azalması durumunun, sigara kullanımıyla birlikte POML oluşumu için gerekli koşulları oluşturduğu düşünülebilir. Sigara kullanımının incelendiği diğer çalışmalarda da sigaranın POML için güçlü predispozan faktörlerden olduğu gösterilmiştir. ${ }^{16,30}$

HP kullanan hastalarda sorgulanan diğer bir durum ise gece protez kullanımıydı. Gece protez takmayan bireylerin \%18,8'inde POML görülürken, gece protezini çıkarmayan hastaların \%60'ında POML görülmüştür. Gece protez kullanımı hastanın oral hijyenini negatif yönde etkileyen, protez altındaki dokuların irritanlara uzun süreli maruz kalmasına sebep olan POML oluşumunda çok önemli derecede etkili bir predispozandır. ${ }^{8}$ Bu sorunun çözümünde diş hekimlerinin hastalara protez kullanım talimatlarını ve bunların önemini vurgulaması önemli olduğu düşünülmektedir. ${ }^{21}$ Gece protez kullanımıyla POML arasında diğer çalışmalarla da desteklenen güçlü bir anlamlılık ilişsisi saptanmıştır. 8,16,24

\section{SONUÇ}

Cinsiyet, protez kullanım süresi, protez temizleme sıklığı, sigara kullanımı ve gece protez kullanma alışkanlığı ile POML ilişkili bulunmuştur. Hareketli protezlerin uygun sürede kullanımları ve oral hijyen alışkanlıklarının doğru şekilde sürdürülmesi ile POML sıklığı azaltılabilir. Bu konuda hastaya protetik tedaviyi uygulayan hekimin, ağız içinde protezle ilişkili bu tür lezyonların da gelişebileceğini belirterek hastayı bilgilendirmesi önem taşımaktadır. 


\section{KAYNAKLAR}

1. Petersen PE. Global policy for improvement of oral health in the 21st century - implications to oral health research of World Health Assembly 2007, World Health Organization. Community Dent Oral. 2009;37(1):1-8.

2. Doğan BG, Gökalp S. Tooth loss and edentulism in the Turkish elderly. Arch Gerontol Geriat. 2012;54(2):162-166.

3. Douglass C, Gammon M, Atwood D. Need and effective demand for prosthodontic treatment. J Prosthet Dent. 1988;59(1):94-104.

4. Douglass CW, Shih A, Ostry L. Will there be a need for complete dentures in the United States in 2020. J Prosthet Dent. 2002;87(1):5-8.

5. Zitzmann NU, Hagmann E, Weiger R. What is the prevalence of various types of prosthetic dental restorations in Europe. Clin Oral Implants Res. 2007;18:20-33.

6. Büyüklü F, Babakurban $S T$, Çaylak B, Çakmak Ö. Epulis Fissuratum. ACU Sağlık Bil Derg. 2010;1(4):229-231.

7. Fleishman R, Peles DB, Pisanti S. Oral mucosal lesions among elderly in Israel. J Dent Res. 1985;64(5):831-836.

8. Akkaya N, Çağırankaya B, Dural S. Hareketli protez kullanimi ile ilişkili oral mukoza lezyonlari ve risk faktörleri. Atatürk Üniv Dis Hek Fak Derg. 2019; 29(4):667-675.

9. Jainkittivong $A$, Aneksuk $V$, Langlais R. Oral mucosal conditions in elderly dental patients. Oral Dis. 2002;8(4):218-223.

10. Gendreau L, Loewy ZG. Epidemiology and etiology of denture stomatitis. J Prosthodont. 2011;20(4):251-260.

11. Kossioni AE. The prevalence of denture stomatitis and its predisposing conditions in an older Greek population. Gerodontology. 2011;28(2):85-90.

12. Shulman J, Rivera-Hidalgo F, Beach M. Risk factors associated with denture stomatitis in the United States. J Oral Pathol Med. 2005;34(6):340-346.

13. Baran I, Nalçacı R. Self-reported denture hygiene habits and oral tissue conditions of complete denture wearers. Arch Gerontol Geriat. 2009;49(2):237-241.

14. Coelho C, Sousa Y, Dare A. Denture-related oral mucosal lesions in a Brazilian school of dentistry. J Oral Rehabil. 2004;31(2):135-139.

15. Tamarit-Borrás $M$, Delgado-Molina E, Berini-Aytés L, Gay-Escoda C. Removal of hyperplastic lesions of the oral cavity. A retrospective study of 128 cases. Med Oral Patol Oral Cir Bucal. 2005;10(2):151-162.

16. Ozec I, Tasveren S, Yeler D, Kilic E. Sivas' ta 40 yaş üzeri bireylerde ağız mukozası lezyonlarının yaygınlığının değerlendirilmesi. Cumhuriyet Dent J. 2008;11(1):10-15.

17. Özeç İ, Kılıç E. Nadir Lokalizasyonda Görülen Epulis fissuratum (Vaka raporu). Cumhuriyet Dent J. 2004; 7(1):34-36

18. MacEntee MI. The prevalence of edentulism and diseases related to dentures-a literature review. J Oral Rehabil. 1985;12(3):195-207.
19. Xie Q, Närhi TO, Nevalainen JM, Wolf J, Ainamo A. Oral status and prosthetic factors related to residual ridge resorption in elderly subjects. Acta Odontol Scand. 1997;55(5):306-313.

20. Park KK, Brodell RT, Helms SE. Angular cheilitis, part 2: nutritional, systemic, and drug-related causes and treatment. Cutis. 2011;88(1):27-32.

21. Brantes MF, Azevedo RS, Rozza-de-Menezes RE, Póvoa HC, Tucci R, Gouvêa AF, et al. Analysis of risk factors for maxillary denture-related oral mucosal lesions: A cross-sectional study. Med Oral Patol Oral Cir Bucal. 2019;24(3):305.

22. AL-Dwairi ZN. Prevalence and risk factors associated with denture-related stomatitis in healthy subjects attending a dental teaching hospital in North Jordan. J Ir Dent Assoc. 2008;54(2):80-83.

23. Mandali G, Sener ID, Turker SB, Ülgen H. Factors affecting the distribution and prevalence of oral mucosal lesions in complete denture wearers. Gerodontology. 2011;28(2):97-103.

24. Ercalik-Yalcinkaya S, Özcan M. Association between oral mucosal lesions and hygiene habits in a population of removable prosthesis wearers. J Prosthodont. 2015;24(4):271-278.

25. Dundar N, Kal BI. Oral mucosal conditions and risk factors among elderly in a Turkish school of dentistry. Gerontology. 2007;53(3):165-172.

26. Mikkonen $M$, Nyyssönen $V$, Paunio I, Rajala M. Prevalence of oral mucosal lesions associated with wearing removable dentures in Finnish adults. Community Dent Oral. 1984;12(3):191-194.

27. Campisi G, Margiotta V. Oral mucosal lesions and risk habits among men in an Italian study population. J Oral Pathol Med. 2001;30(1):22-28.

28. Gendreau L, Loewy ZG. Epidemiology and Etiology of Denture Stomatitis. J Prosthodont. 2011;20(4):251-260.

29. Coelho CMP, Sousa YTCS, Daré AMZ. Denture-related oral mucosal lesions in a Brazilian school of dentistry. J Oral Rehabil. 2004;31(2):135-139.

30. Bozdemir E, Yilmaz HH, Orhan H. Oral mucosal lesions and risk factors in elderly dental patients. J Dent Res Dent Clin Dent Prospects. 2019;13(1):24.

31. Budtz-Jørgensen E. Oral mucosal lesions associated with the wearing of removable dentures. $J$ Oral Pathol Med. 1981;10(2):65-80.

32. Moskona D, Kaplan I. Oral lesions in elderly denture wearers. Clin Prev Dent. 1992;14(5):11-14.

33. Axe AS, Varghese R, Bosma M, Kitson N, Bradshaw DJ. Dental health professional recommendation and consumer habits in denture cleansing. J Prosthet Dent. 2016;115(2):183-188.

34. Sesma N, Takada K, Laganá D, Jaeger R, Azambuja J. Evaluation of the efficacy of cleansing methods for 
removable partial dentures. Rev Assoc Paul Cir Dent. 1999;53(6):463-468.

35. Peltola M, Raustia A, Salonen M. Effect of complete denture renewal on oral health-a survey of 42 patients. J Oral Rehabil. 1997;24(6):419-425.

36. Jagger $D$, Harrison A. Denture cleansing--the best approach. Br Dent J. 1995;178(11):413. 